\title{
Rapid dike intrusion into Sakurajima volcano on August 15, 2015, as detected by multi-parameter ground deformation observations
}

\author{
Kohei Hotta ${ }^{*}$, Masato Iguchi and Takeshi Tameguri
}

\begin{abstract}
We present observations of ground deformation at Sakurajima in August 2015 and model the deformation using a combination of GNSS, tilt and strain data in order to interpret a rapid deformation event on August 15, 2015. The pattern of horizontal displacement during the period from August 14 to 16, 2015, shows a WNW-ESE extension, which suggests the opening of a dike. Using a genetic algorithm, we obtained the position, dip, strike length, width and opening of a dislocation source based on the combined data. A nearly vertical dike with a NNE-SSW strike was found at a depth of $1.0 \mathrm{~km}$ below sea level beneath the Showa crater. The length and width are 2.3 and $0.6 \mathrm{~km}$, respectively, and a dike opening of $1.97 \mathrm{~m}$ yields a volume increase of $2.7 \times 10^{6} \mathrm{~m}^{3} .887$ volcano-tectonic (VT) earthquakes beside the dike suggest that the rapid opening of the dike caused an accumulation of strain in the surrounding rocks, and the VT earthquakes were generated to release this strain. Half of the total amount of deformation was concentrated between 10:27 and 11:54 on August 15. It is estimated that the magma intrusion rate was $1 \times 10^{6} \mathrm{~m}^{3} / \mathrm{h}$ during this period. This is 200 times larger than the magma intrusion rate prior to one of the biggest eruptions at the summit crater of Minami-dake on July 24, 2012, and 2200 times larger than the average magma intrusion rate during the period from October 2011 to March 2012. The previous Mogi-type ground deformation is considered to be a process of magma accumulation in preexisting spherical reservoirs. Conversely, the August 2015 event was a dike intrusion and occurred in a different location to the preexisting reservoirs. The direction of the opening of the dike coincides with the T-axes and direction of faults creating a graben structure.
\end{abstract}

Keywords: Sakurajima volcano, Ground deformation, GNSS, Tilt and strain, Dike intrusion

\section{Introduction}

Sakurajima is an andesitic volcano with two central cones, Kita-dake and Minami-dake, located on the southern rim of the Aira caldera, southern Kyushu, Japan (Fig. 1). The Showa crater, which is located approximately $500 \mathrm{~m}$ east of the Minami-dake crater, resumed eruptive activity in June 2006, and vulcanian eruptions gradually increased in the autumn of 2009, as shown in Fig. 2. The increase in explosive eruptive activity at the crater was accompanied by ground inflation at the Aira caldera and Sakurajima.

${ }^{*}$ Correspondence: hotta.kohei.7r@kyoto-u.ac.jp

Sakurajima Volcano Research Center, Disaster Prevention Research

Institute, Kyoto University, Kagoshima, Kagoshima 891-1419, Japan
Two inflation sources were estimated to exist at depths of 12 and $5 \mathrm{~km}$ beneath the Aira caldera and Kita-dake, respectively, based on global navigation satellite system (GNSS) observation campaigns (Iguchi et al. 2013). A similar ground inflation event was also detected during the period from late 2011 to early 2012 when eruptive activity increased again. After the start of the ground inflation event from late 2011, activity at the Showa crater remained at a heightened level with frequent eruptions until the end of 2013. The number of explosive eruptions decreased in 2014, but increased again from January 2015 with further ground inflation. From March 31 to early April 2015, volcano-tectonic (VT) earthquakes occurred frequently in the southwestern part of Sakurajima. This 


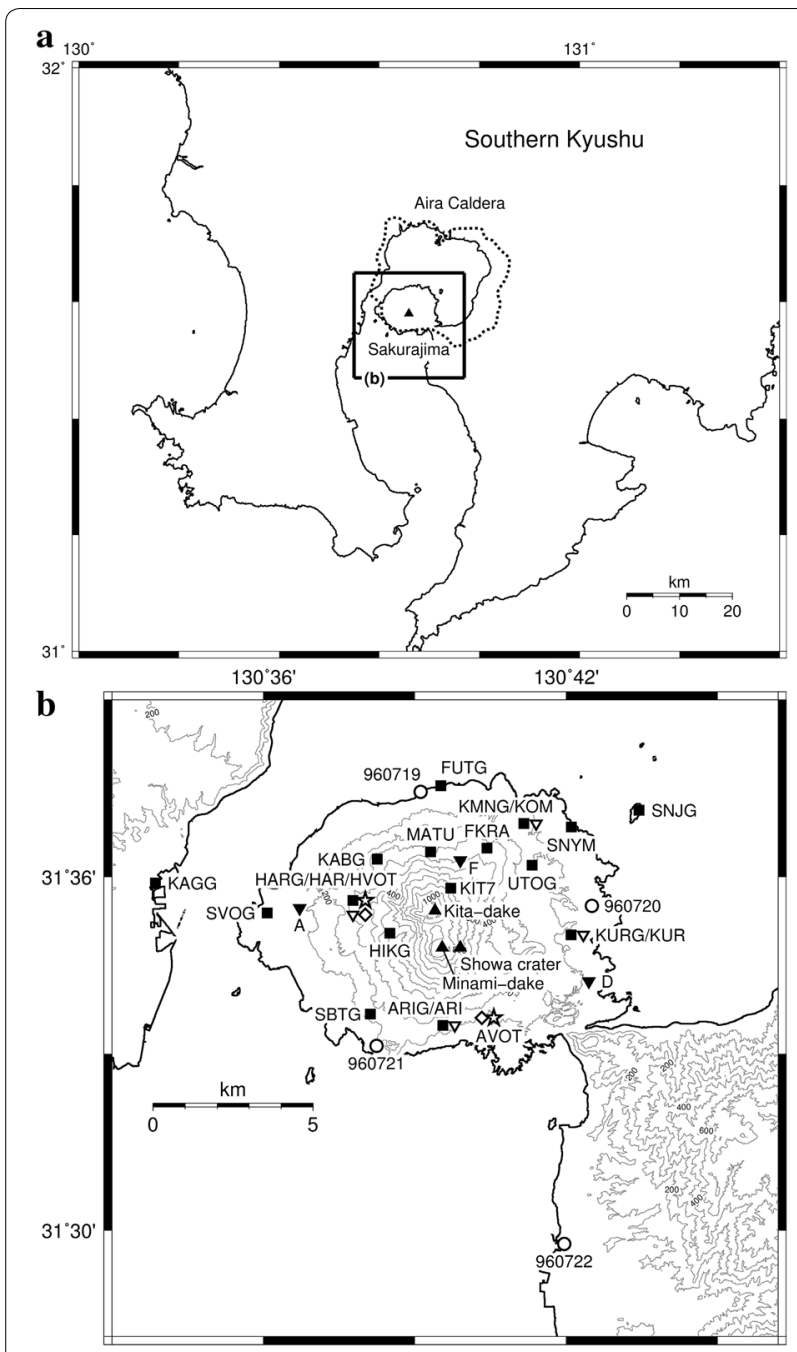

Fig. 1 a Location of Sakurajima volcano and Aira caldera. The solid triangle represents the summit crater of Minami-dake; the dashed line represents the rim of the Aira caldera. $\mathbf{b}$ Magnification of box in (a). Solid squares represent the continuous global navigation satellite system (GNSS) stations of the Sakurajima Volcano Research Center (SVRC) of Kyoto University; open circles represent GEONET stations operated by the Geospatial Information Authority of Japan (GSI); open rhombuses represent the water-tube tiltmeters; open inverted triangles represent the borehole tiltmeter from the SVRC; solid inverted triangles represent the borehole tiltmeter from the Japan Meteorological Agency (JMA); open stars represent linear strainmeters; and solid triangles represent Kita-dake, Minami-dake and the Showa crater

seismicity is similar to that in 2003-2004, which preceded the start of eruptive activity at the Showa crater in June 2006 (Hidayati et al. 2007), and 1976-1978 when vulcanian activity at the summit crater of Minami-dake was increasing (Kamo 1978). From July 2015, eruptive activity at the Showa crater was decreasing. On August 15,2015 , sudden ground deformation was detected in the tilt and strain data, accompanied by a significant increase in VT earthquake activity, with 887 events occurring within the day. The maximum magnitude of the events was 2.3. GNSS data showed a WNW-ESE extension up to $6 \mathrm{~cm}$ on the day. This event led to the alert level of the Japan Meteorological Agency (JMA) for Sakurajima volcano being upgraded from three to four. An evacuation advisory was issued for residents in Sakurajima by Kagoshima city government, and 77 residents evacuated.

In this study, we present observations of rapid ground deformation in August 2015 and model the deformation using GNSS, tilt and strain data in order to interpret the event.

\section{Observation and data}

We used 20 GNSS stations: 16 GNSS stations from the Sakurajima Volcano Research Center (SVRC) of Kyoto University and 4 GNSS Earth Observation Network (GEONET) stations (Fig. 1b). We used the L1 and L2 GPS frequency bands. Daily positions of the stations were calculated using Leica GNSS Spider Version 5.2 (automatic) and Leica Geo Office 8.2 (manual). Sampling intervals of $1 \mathrm{~s}$ were used. In addition to the GNSS data, we also used data obtained from 2 sets of water-tube tiltmeters, 7 borehole tiltmeters and 2 sets of linear strainmeters (Fig. 1b). The tiltmeters and strainmeters operated by the SVRC were positioned radially and tangentially to the Minami-dake crater (the radial components were positive toward the Minami-dake crater, and the tangential components were positive in the direction rotated $90^{\circ}$ clockwise from the radial components), and 3 borehole tiltmeters operated by the JMA were installed in the north and east directions. The water-tube tiltmeters and linear strainmeters were installed in the 400-m-long Arimura underground tunnel (AVOT) operated by the Ministry of Land, Infrastructure, Transport and Tourism of Japan (MLIT) and the 250-m-long Harutayama underground tunnel (HVOT). The span of each component was $28 \mathrm{~m}$. Sensitivities were $0.056 \mathrm{~V} / \mu \mathrm{rad}$ for the water-tube tiltmeters and $0.056 \mathrm{~V} / \mu$ strain for the linear strainmeters. The sensitivity of borehole tiltmeters was $0.02 \mathrm{~V} / \mu \mathrm{rad}$. Borehole tiltmeters were installed at depths of $85-350 \mathrm{~m}$. The analog-to-digital resolution for all tiltmeters and strainmeters was 24 bit.

\section{Ground deformation and seismicity during the deformation event}

The seismicity from the VT earthquakes started at 7:05 on August 15, changes in the tilt and strain started at around 8:00 (Fig. 3), and 9 earthquakes ( $>10 \mu \mathrm{m} / \mathrm{s}$ at the Arimura station, which was located in the AVOT, Fig. 1b) occurred before 8:00 (Fig. 4). At 8:54, the deformation rate increased for the second time. The deformation rate during the second deformation stage then gradually 

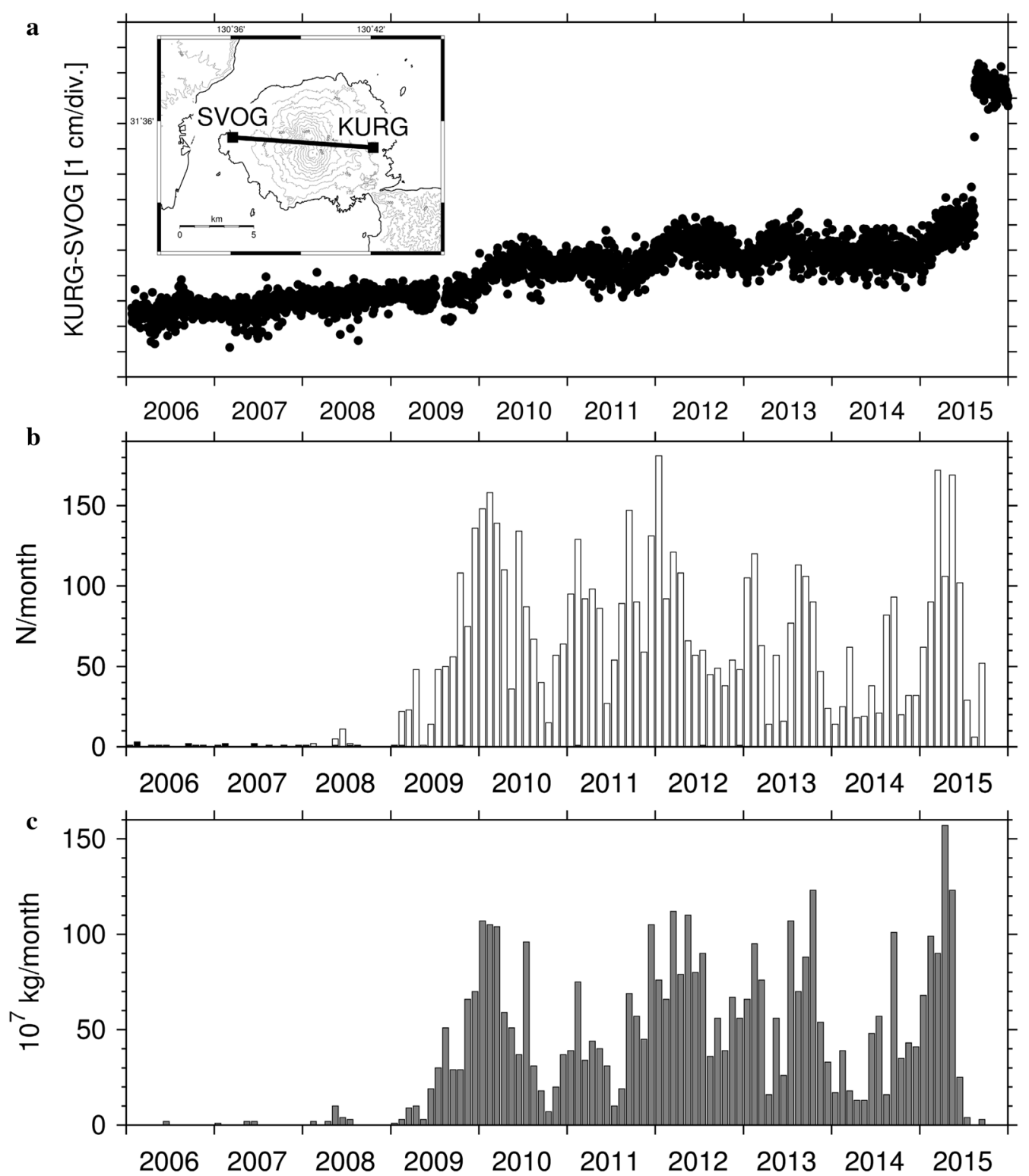

Fig. 2 a Change in horizontal distance between GNSS stations KURG and SVOG during the period from January 2006 to December 2015. Errors of these data are $\leq 0.2 \mathrm{~cm}$. b Monthly number of explosions from January 2006 to December 2015. Black bars represent explosions at the summit crater of Minami-dake, and white bars represent explosions at the Showa crater. c Monthly weight of volcanic ash ejected from January 2006 to December 2015 estimated by the SVRC using the method proposed by Eto (2001)

decreased until 10:27 when it began to rapidly increase again. The third increase in the deformation rate was the largest of the three increases and continued until 11:54. Here changes in the radial tilt at the AVOT and HVOT attained 29 and $5 \mu \mathrm{rad}$, respectively, in only $87 \mathrm{~min}$ (Fig. 3b, c). After 11:54, the rate of change of tilt and strain gradually decreased. The rate of change of the tilt and strain became small, $<0.4 \mu \mathrm{rad} / \mathrm{h}$, on August 16, and was almost zero on August 17. The total changes in radial tilt at AVOT and HVOT were 58 and $13 \mu \mathrm{rad}$ toward
Minami-dake, respectively. After August 17, the tilt and strain remained constant and did not return to the same levels as before the deformation event, which imply intruded magma remained beneath Sakurajima without being ejected to the surface. As the tangential tilt at the HVOT did not show a significant change, the tilt vector at the station was oriented toward the Minami-dake crater. The tangential tilt at AVOT showed a remarkable change of $38 \mu \mathrm{rad}$. The tilt vector deviated by approximately $30^{\circ}$ east of the direction of the Minami-dake crater. This is 


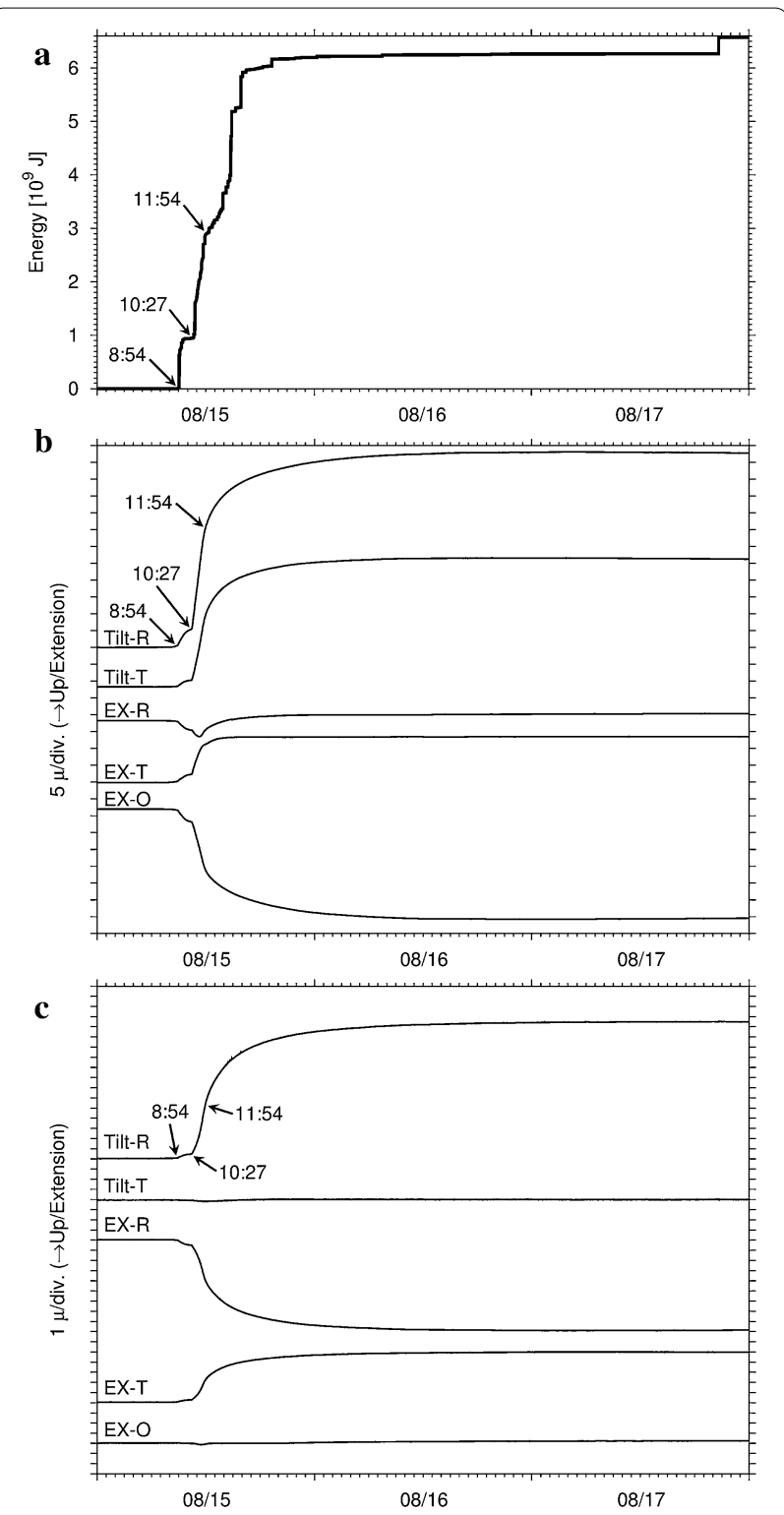

Fig. 3 Seismicity and ground deformation during the period from August 15 to 17, 2015. a Cumulative seismic energy. b Tilt and strain change at the AVOT. Tilt-R and Tilt-T represent radial and tangential tilt, respectively; EX-R, EX-T and EX-O represent radial, tangential and oblique strain, respectively. Errors of these data are $\leq 0.2 \mu$. c Tilt and strain change at the HVOT. Errors of these data are $\leq 0.2 \mu$

unlike the ground deformation usually associated with vulcanian eruptions at the Minami-dake and Showa craters, which have a very small change of tangential tilt at AVOT [for example, eruptions at the Showa crater during August 6-9, 2009, resulted in a change in the tangential tilt at the AVOT of $<10$ nrad (Yokoo et al. 2013)].

Along with the second increase in the deformation rate at 8:54, the seismicity of VT earthquakes also increased.

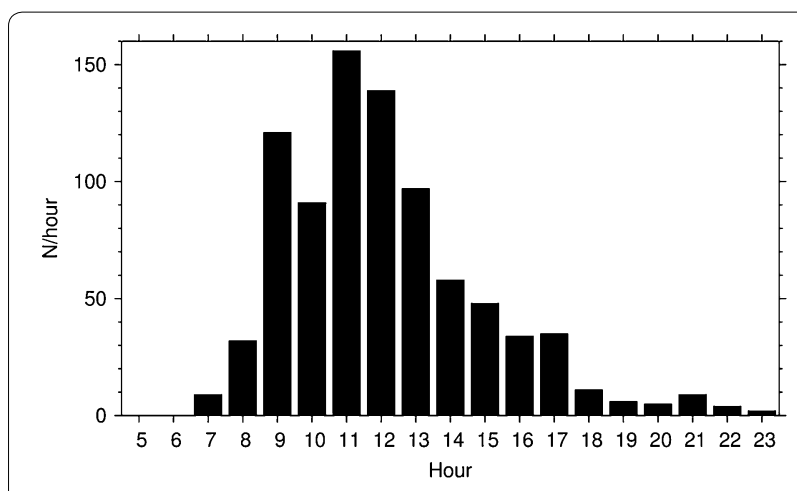

Fig. 4 Hourly number of $\mathrm{VT}$ earthquakes during the period from 5:00 to $23: 59$ on August 15, 2015

During the period with the highest deformation rate from 10:27 to $11: 54$, the seismicity drastically increased, including the largest earthquake at 10:47 (M2.3). After 11:54, the seismicity decreased except for the felt earthquakes at 14:39, 14:46 and 14:52, after which, only 73 earthquakes occurred on August 16.

Such large deformation, as indicated by the change in the tilt and strain, was also detected by GNSS. Temporal changes in daily positions at some sites relative to SVOG, in addition to changes in the tilt and strain at the HVOT, during the period from July 1 to September 1, 2015, are shown in Fig. 5. The positions of the GNSS sites suddenly shifted on August 15, 2015. Before August 14, no significant deformation was detected. During the period from August 14 to 16, more than half of the stations moved significantly: KURG, located in eastern Sakurajima, moved $6 \mathrm{~cm}$ eastward; ARIG, located in southeastern Sakurajima, moved $3 \mathrm{~cm}$ toward the south; and HARG $2.7 \mathrm{~km}$ northwest of the summit crater of Minami-dake moved 2 and $4 \mathrm{~cm}$ toward the north and west, respectively. Conversely, north to northeastern (FUTG, KMNG) and southwestern (SBTG) parts of Sakurajima showed no significant displacements during this event. Vectors for the horizontal displacements, with reference to station 960722, for the period from August 14 to 16, 2015 are summarized in Fig. 6. Outward movements from the summit are primarily in the northwest and southeast regions. After August 17, ground deformation stopped at all stations.

\section{Analysis and results}

The pattern of horizontal displacements shows a WNWESE extension, which suggests a tensile fault rather than the isotropic pressure source implied from radial displacement patterns around Sakurajima and the Aira caldera in previous studies which located pressure sources beneath the Aira caldera, Kita-dake and Minami-dake 

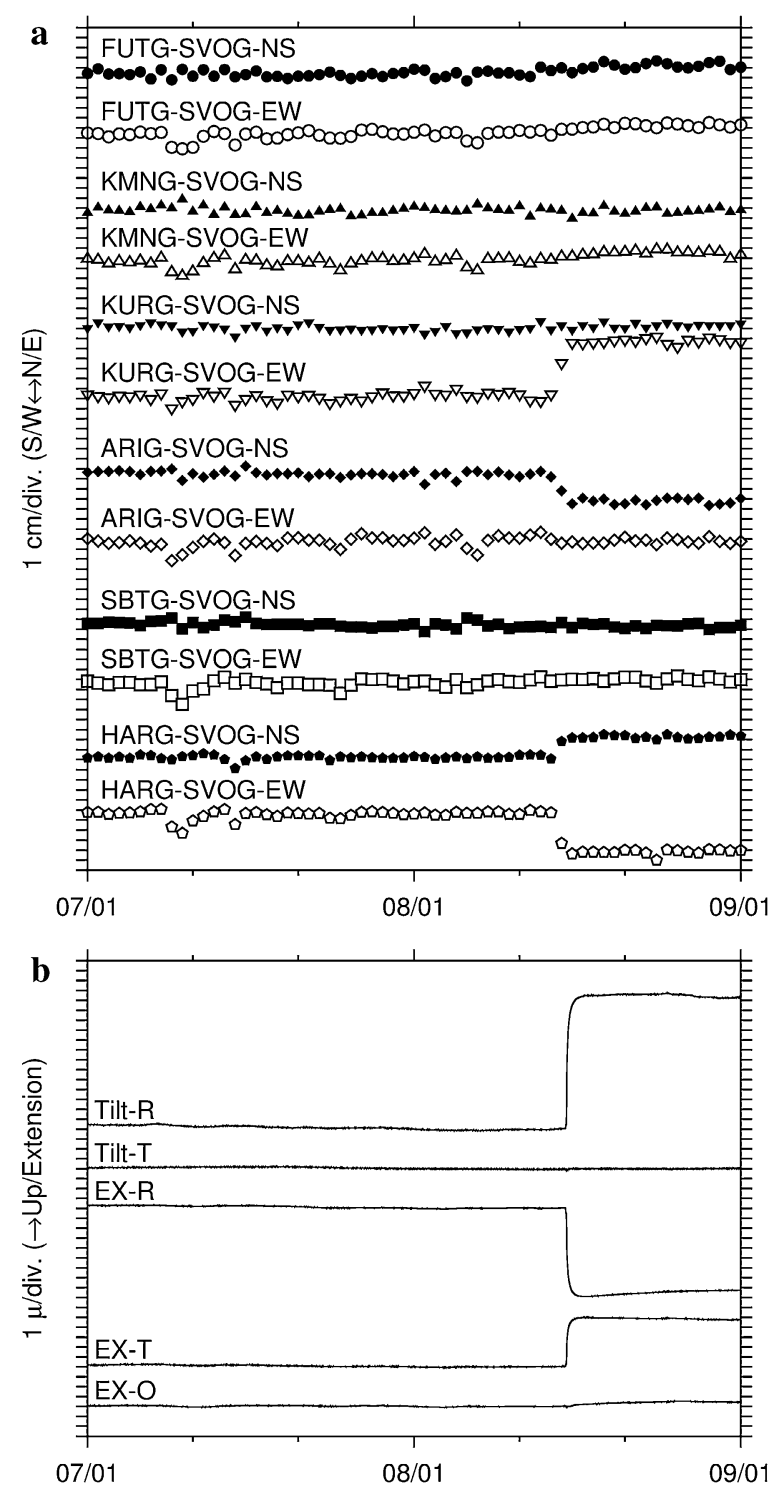

Fig. 5 a Temporal change in relative position with reference to SVOG during the period from July 1 to September 1, 2015. Errors of these data are as described in Fig. 2a. b Tilt and strain change at HVOT during the same period. Tilt-R, Tilt-T, EX-R, EX-T and EX-O are the same as described in Fig. 2b. Errors of these data are as described in Fig. 3b, C

(e.g., Iguchi et al. 2013; Yamamoto et al. 2013; Hotta et al. 2016). Thus, we applied the dislocation source model for a half-infinite homogeneous elastic solid with a Poisson coefficient of 0.25 (Okada 1992). Neglecting the topographical effect at stations located further from the summits of central cones should not have significantly affected the results (Jousset et al. 2003). Although neglecting the topographical effect might slightly affect the results as for some stations near summit crater, we neglected the topographical effect for all stations in the

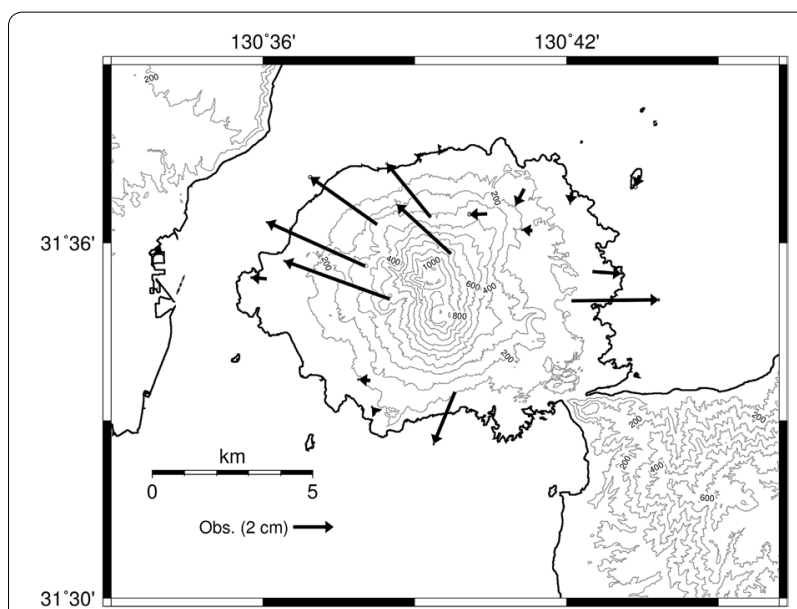

Fig. 6 Horizontal displacement vector with reference to station 960722 during the period from August 14 to 16, 2015. Errors ellipses are 10

present study for simplicity. We excluded vertical data of GNSS because our observation could not detect significant vertical deformation (within $\pm 0.6 \mathrm{~cm}$ ) compared to their error $(>1 \mathrm{~cm})$. Using a genetic algorithm (e.g., Tiampo et al. 2000; Hotta et al. 2016), we searched for optimal parameters for position, dip, strike, length, width and opening of the source. We set the number of individuals at 50; the probabilities of crossover, jump mutation and creep mutation at 70, 2 and $18 \%$, respectively; and the number of iterations for the genetic algorithm at 200,000. In order to avoid a local minimum, we executed the iteration process several times (Hotta et al. 2016). In order to minimize the difference between the observed and calculated values, a fitting function $f$ was defined as follows:

$$
f=\frac{R d^{2}}{C}+\frac{R \delta^{2}+R \varepsilon^{2}}{S}
$$

where

$R d^{2}=\sum_{1 \leq i<j \leq 20}\left\{\left(\frac{d N_{o b s}^{i, j}-d N_{c a l}^{i, j}}{\sigma d N^{i, j}}\right)^{2}+\left(\frac{d E_{o b s}^{i, j}-d E_{c a l}^{i, j}}{\sigma d E^{i, j}}\right)^{2}\right\}$,

$R \delta^{2}=\sum_{1 \leq k \leq 9}\left\{\left(\frac{\delta R_{o b s}^{k}-\delta R_{c a l}^{k}}{\sigma \delta R^{k}}\right)^{2}+\left(\frac{\delta T_{o b s}^{k}-\delta T_{c a l}^{k}}{\sigma \delta T^{k}}\right)^{2}\right\}$,

$R \varepsilon^{2}=\sum_{1 \leq m \leq 2}\left\{\left(\frac{\varepsilon R_{o b s}^{m}-\varepsilon R_{c a l}^{m}}{\sigma \varepsilon R^{m}}\right)^{2}+\left(\frac{\varepsilon T_{o b s}^{m}-\varepsilon T_{c a l}^{m}}{\sigma \varepsilon T^{m}}\right)^{2}\right\}$ 
and where $C(=190)$ is the number of combinations among the 20 GNSS stations; $S(=11)$ is the total number of tilt (9) and strain (2) stations; subscripts obs and cal indicate the observed and calculated values, respectively; $d N^{i, j}$ and $d E^{i, j}$ are the north-south and east-west components of the relative displacements of the $i$-th GNSS station with respect to the $j$-th one; $\delta R^{k}$ and $\delta T^{k}$ are the radial and tangential components of the $k$-th tiltmeter, which is installed in the directions radial and tangential to Minami-dake; $\varepsilon R^{m}$ and $\varepsilon T^{m}$ are the radial and tangential components of the $m$-th strainmeter; and $\sigma$ indicates the observation error. The search spaces and step sizes for the parameter estimates are given in Table 1.

The optimal parameters and $95 \%$ confidence intervals that were obtained are given in Table 1 , and the source location and a comparison of the observations and calculations are shown in Fig. 7. Figure 8 shows contour maps of the fitting function $f$ for the parameter spaces of the dike depth and opening, and dike length and width. The parameters for the source are well constrained for the obtained values (Table 1). A nearly vertical dike with a NNE-SSW strike is located at a depth of $1.0 \mathrm{~km}$ below sea level beneath the Showa crater. The length and width of the dike are 2.3 and $0.6 \mathrm{~km}$, respectively. The opening of $1.97 \mathrm{~m}$ yields a volume increase of $2.7 \times 10^{6} \mathrm{~m}^{3}$. This dike model can well explain the tendency of WNW-ESE extension although there are some differences between the observations and calculations within the data error (Fig. 7a). For tilt and strain, the directions of calculated upward change are almost the same as the observations (Fig. 7b, c), although there are some differences in the magnitude of the changes within the data error. Possible reasons for the differences between the observations

Table 1 Search space, step size, parameter estimates and their $95 \%$ confidence intervals obtained from the GNSS, tilt and strain data

\begin{tabular}{llll}
\hline Parameter & Range & Step & Estimated value \\
\hline Position E-W & -20.0 to $20.0 \mathrm{~km}$ & $0.1 \mathrm{~km}$ & $\begin{array}{l}0.8 \pm 0.1 \mathrm{~km} \\
\left(130.6684^{\circ} \mathrm{E}\right)\end{array}$ \\
Position N-S & -20.0 to $20.0 \mathrm{~km}$ & $0.1 \mathrm{~km}$ & $\begin{array}{l}-0.3 \pm 0.2 \mathrm{~km} \\
\left(31.5773^{\circ} \mathrm{N}\right)\end{array}$ \\
Depth & 0.0 to $20.0 \mathrm{~km}$ & $0.1 \mathrm{~km}$ & $1.0 \pm 0.1 \mathrm{~km}$ \\
Dip & $0^{\circ}$ to $90^{\circ}$ & $1^{\circ}$ & $74^{\circ} \pm 4^{\circ}$ \\
Strike & $0^{\circ}$ to $359^{\circ}$ & $1^{\circ}$ & $34^{\circ} \pm 4^{\circ}$ \\
Length & 0.0 to $20.0 \mathrm{~km}$ & $0.1 \mathrm{~km}$ & $2.3 \pm 0.2 \mathrm{~km}$ \\
Width & 0.0 to $20.0 \mathrm{~km}$ & $0.1 \mathrm{~km}$ & $0.6 \pm 0.1 \mathrm{~km}$ \\
Opening & -20.0 to $20.0 \mathrm{~m}$ & $0.01 \mathrm{~m}$ & $1.97 \pm 0.27 \mathrm{~m}$ \\
\hline
\end{tabular}

The uncertainties are the $95 \%$ confidence intervals estimated from an $F$ test (Árnadóttir and Segall, 1994). The origin of the horizontal coordinates is fixed at the summit crater of Minami-dake $\left(130.66^{\circ} \mathrm{E}, 31.58^{\circ} \mathrm{N}\right)$. The position of the dislocation model is at the center of the top edge of the fault. The dip is clockwise from the horizontal, and the strike is clockwise from the north
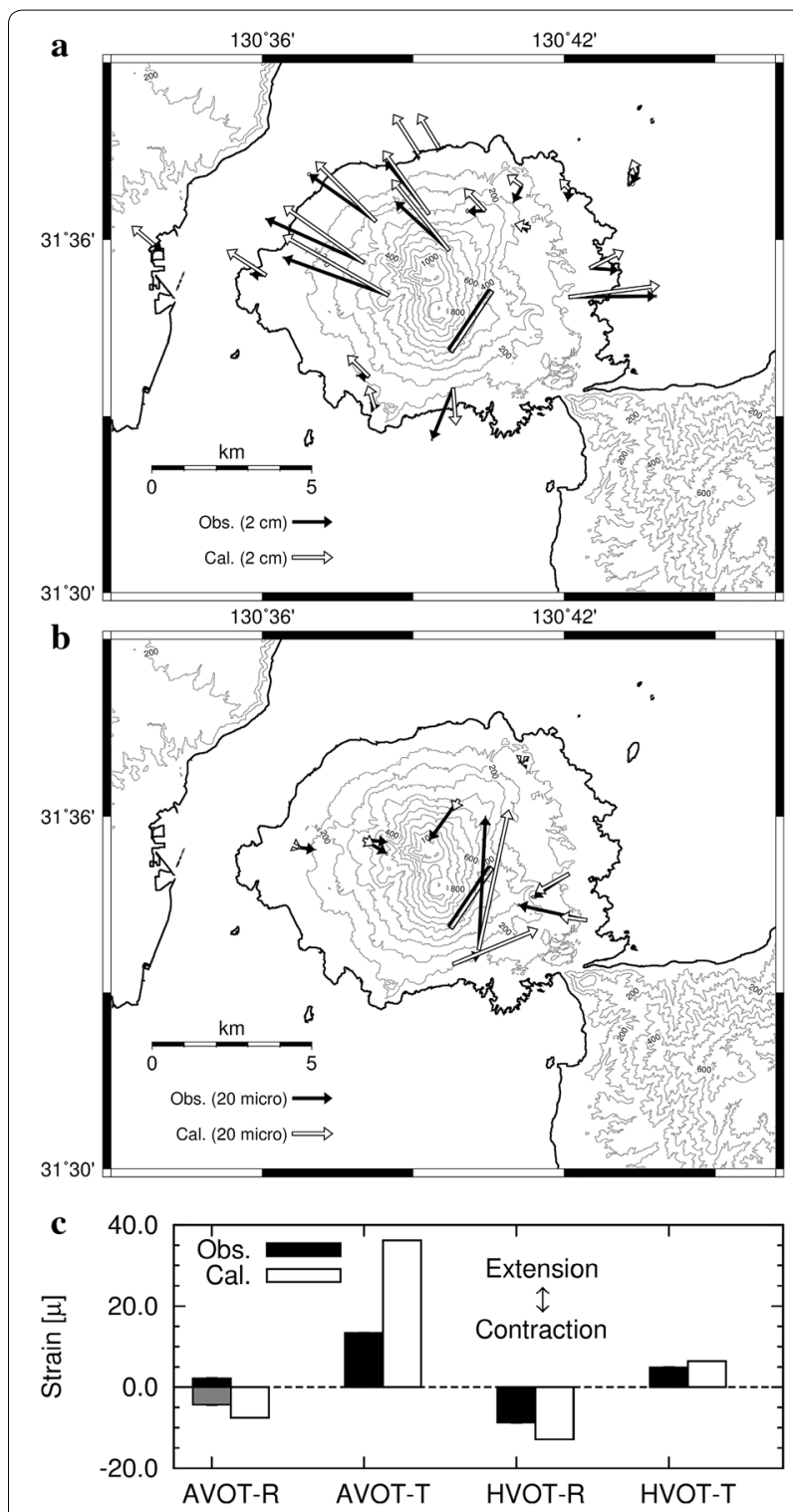

Fig. 7 a Location of the obtained dike (the solid rectangle). The thick black line represents the top of the obtained dike. Arrows indicate observed (black) and calculated (white) horizontal displacements with reference to station 960722 during the period from August 14 to 16,2015 . Error ellipses are 10. b Comparison of observed (black arrows) and calculated (white arrows) tilt change. Error ellipses are $1 \sigma$. c Observed (black bars) and calculated (white bars) strain change. The gray bar at AVOT-R represents the observed radial tilt change until 11:54 of August 15. Error bars are 10

and calculations are plastic deformation, which is known to result in larger deformation compared to purely elastic deformation (Currenti et al. 2010), or limitations due to neglecting heterogeneities (e.g., Zhao et al. 2004; Hickey et al. 2013). The observed extension strain in the radial component at the AVOT is different from the calculated contraction strain. We note, however, that the 

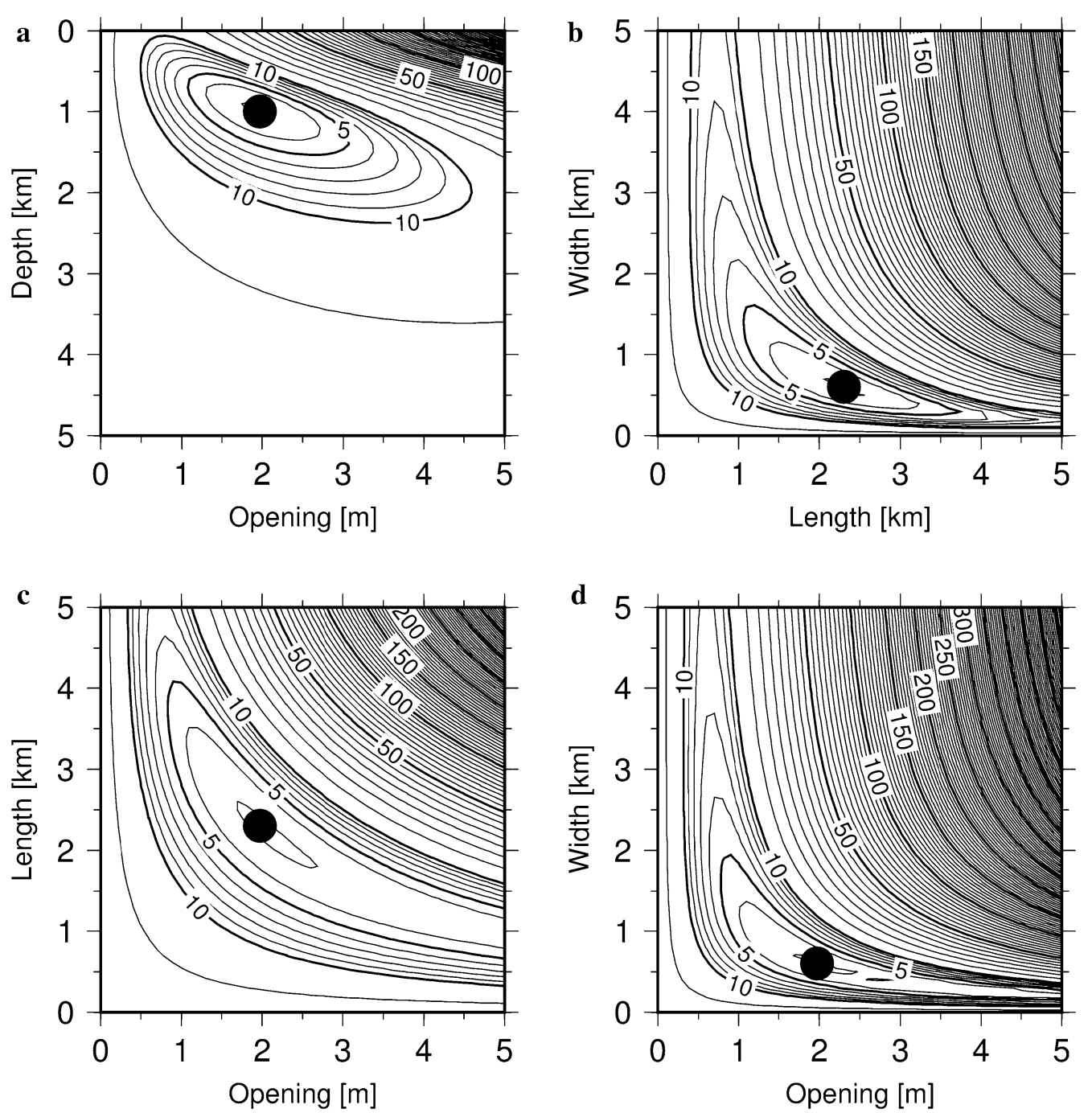

Fig. 8 Contour maps of the fitting function $f$ [Eqs. (1)-(4)] in $10^{4}$ for the parameter spaces of a dike depth and opening, $\mathbf{b}$ dike length and width, c dike length and opening and $\mathbf{d}$ dike width and opening. Dots represent the optimal points $\left(f=2.9 \times 10^{4}\right)$, and the $95 \%$ confidence intervals estimated from an $F$ test (Árnadóttir and Segall 1994) are the range of $f \leq 3.2 \times 10^{4}$

radial strain at the AVOT is contracting before the third increase in deformation, until 11:54 (Fig. 3b). The calculated contraction of the radial strain at the AVOT is thought to correspond to the observed contraction. The change in the radial strain at the AVOT might be due to complex geometry or migration of the dike.

\section{Discussion and conclusion}

The rapid ground deformation on August 15 can be modeled by the opening of a dike striking in a NNE-SSW direction at a shallow depth beneath the Showa crater. The deformation was accompanied by 887 VT earthquakes on the same day. Figure 9 shows the hypocenters of earthquakes during the period from August 15 to
19, 2015. The hypocenters are located using the method of Hirata and Matsu'ura (1987) under the assumption of a homogeneous half-space with $V_{p}=2.5 \mathrm{~km} / \mathrm{s}$ and $V_{p} / V_{s}=1.73$. We used $\geq 12$ readable $\mathrm{P}$-wave onsets and $\geq 6$ readable $\mathrm{S}$-wave onsets at the stations as shown in Fig. 9a. The distribution of hypocenters beneath the summit crater of Minami-dake is similar to that obtained in previous studies (e.g., Hidayati et al. 2007). The hypocenters are adjacent to the obtained dike, but do not share the same location. The locations of the hypocenters delineate the eruptive magma conduit that connects the summit crater and the magma reservoir beneath the crater (e.g., Iguchi et al. 2013), as the repeated passing of heated magma makes the surrounding rocks fragile by 

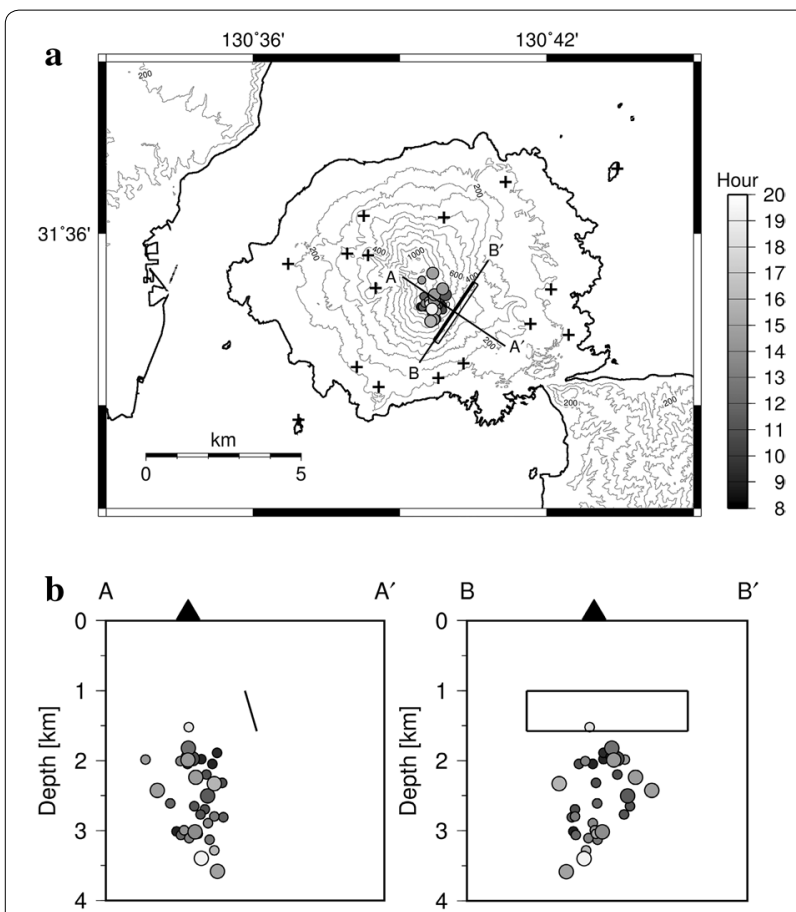

Fig. 9 Hypocenters of VT earthquakes on August 15, 2015. Small circles represent $1 \leq M<2$ events and large ones represent $M \geq 2$ events. The grayscale represents occurrence time of each event. The solid rectangle in (a) represents the location of the obtained dike. Crosses are seismic stations. Hypocenters of small VT earthquakes $(M<1)$ are not plotted because they cannot be accurately located. $\mathbf{b}$ Hypocenters projected on cross sections of $A-A^{\prime}$ and $B-B^{\prime}$ in (a). Solid triangles represent the position of Minami-dake

the repetition of heat up and cool down. We infer that magma intruded into the obtained dike, where rapid opening resulted in an accumulation of strain in the surrounding rocks, and the VT earthquakes were generated at fragile places beneath Minami-dake and around the usual eruptive conduit to release the accumulated strain.

The most rapid deformation was observed from 10:27 to 11:54 on August 15. Half of the total amount of deformation was concentrated within this 1.5 -h period. It is estimated that the magma intrusion rate was $1 \times 10^{6} \mathrm{~m}^{3} / \mathrm{h}$ during this period. The magma intrusion volume beneath Minami-dake prior to the vulcanian eruption on July 24, 2012, one of the biggest eruptions at the Minami-dake crater, was $1 \times 10^{5} \mathrm{~m}^{3}$ (Iguchi 2013). The deformation that accompanied this intrusion continued without interruption for $21 \mathrm{~h}$, and an intrusion rate of $5 \times 10^{3} \mathrm{~m}^{3} / \mathrm{h}$ was obtained. The intrusion rate for the event on August 15, 2015, was 200 times larger than that on July 24, 2012. The ground deformation during the period from October 2011 to March 2012 was one of the largest long-term deformation events after the resumption of eruptive activity at the Showa crater on June 2006. Hotta et al. (2016) found that the magma intrusion volume toward Sakurajima beneath the Kita-dake crater during this six-month period was $2 \times 10^{6} \mathrm{~m}^{3}$, which yields an intrusion rate of $460 \mathrm{~m}^{3} / \mathrm{h}$. The intrusion rate for the event on August 15, 2015, was 2200 times larger than that for the long-term average intrusion during the period from October 2011 to March 2012.

Previously, a combination of spherical sources in an elastic and homogeneous half-space (Mogi 1958) was applied to the observed deformation in and around Sakurajima (e.g., Iguchi et al. 2013; Yamamoto et al. 2013; Hotta et al. 2016). The ground deformation during these observation periods had characteristics suggestive of isotropic sources. The deformation pattern for the August 2015 event, however, is not suitable for applying the Mogi model. The horizontal displacements do not indicate a radial expansion, but a WNW-ESE extension, which is approximated by a nearly vertical dike with a NNE-SSW strike. The previous Mogi-type ground deformation is considered to be a process of magma accumulation in preexisting spherical reservoirs beneath the Minami-dake craters. Conversely, the August 2015 intrusion event was a dike intrusion in a different location to the preexisting reservoirs.

The tensile direction caused by tectonic ground deformation around this area is ESE-WNW (Watanabe and

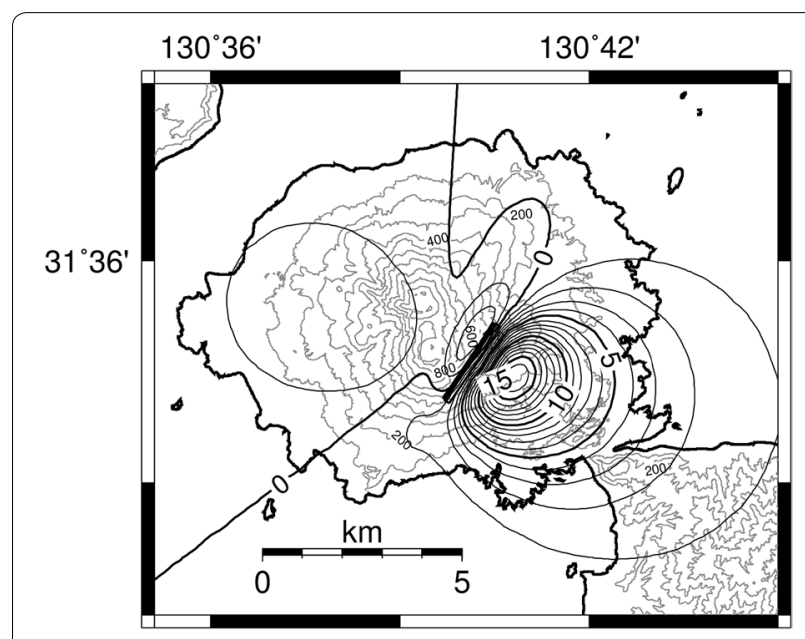

Fig. 10 Distribution of displacement $(\mathrm{cm})$ in the satellite line-of-sight direction for the InSAR observations on January 4 and August 16, 2015, calculated from the obtained dike 
Tabei 2004). The earthquakes at the southwestern part of Sakurajima have normal fault mechanisms with T-axes of ESE-WNW and are considered to be affected by tectonic stress in southern Kyushu (Hidayati et al. 2007). The direction of the opening of the dike coincides with the $\mathrm{T}$-axes and the direction of the faults in the Aira caldera creating the structures of the Kagoshima graben (Hidayati et al. 2007), and influencing the opening direction of the dike that intruded on August 15.

Finally, we compared the calculated value of the dike we obtained from the GNSS, tilt and strain data with the InSAR data. From the InSAR observations, displacement of up to $16 \mathrm{~cm}$ was detected at the eastern flank of Sakurajima during the period from January 4 to August 16, 2015 (Morishita et al. 2016). Figure 10 represents the distribution of the displacement in the satellite line-ofsight direction for the InSAR observations on January 4 and August 16, 2015, calculated from the obtained dike. The dike can explain the displacement of up to $16 \mathrm{~cm}$ at the eastern flank of Sakurajima, which was detected from the InSAR observations, and the obtained dike is consistent with the InSAR data. More precise geometry of intruded dike would be revealed by including InSAR data into our analysis.

\section{Authors' contributions}

$\mathrm{KH}$ participated in the study conception and design, acquisition of data, analysis and interpretation of data and drafted the manuscript. MI participated in the study conception and design, acquisition of data, analysis of data and helped to draft the manuscript with critical revisions. TT participated in the acquisition of data, analysis of data and helped to draft the manuscript with critical revisions. All authors read and approved the final manuscript.

\section{Acknowledgements}

We used GNSS data from Tohoku University managed by Dr. Ohta; GEONET and JPGIS data from the Geospatial Information Authority of Japan; tilt, strain and seismic data from the AVOT station from the Osumi Office of River and National Highway, Kyushu Regional Development Bureau, MLIT; GNSS, tilt and seismic data from the JMA; generic mapping tools (Wessel and Smith 1995); and the program code of Dr. Carroll's FORTRAN genetic algorithm driver (Carroll 1999). We also thank Drs. Yosuke Aoki and James Hickey and an anonymous reviewer for their helpful comments.

\section{Competing interests}

The present study was supported by the Ministry of Education, Culture, Sports, Science and Technology (MEXT) of Japan, under its Earthquake and Volcano Hazards Observation and Research Program.

Received: 5 December 2015 Accepted: 18 April 2016

Published online: 27 April 2016

\section{References}

Árnadóttir T, Segall P (1994) The 1989 Loma Prieta earthquake imaged from inversion of geodetic data. J Geophys Res 99(B11):21835-21855

Carroll DL (1999) FORTRAN genetic algorithm (GA) driver. http://www.cuaerospace.com/Technology/GeneticAlgorithm/GADriverFreeVersion.aspx. Accessed 5 Feb 2016
Currenti G, Bonaccorso A, Negro CD, Scandura D, Boschi E (2010) Elastoplastic modeling of volcano ground deformation. Earth Planet Sci Lett 296:311-318

Eto T (2001) Estimation of the amount and dispersal of volcanic ash-fall deposits ejected by vulcanian type eruption. Rep Fac Sci, Kagoshima Univ 34:35-46

Hickey J, Gottsmann J, del Potro R (2013) The large-scale surface uplift in the Altiplano-Puna region of Bolivia: a parametric study of source characteristics and crustal rheology using finite element analysis. Geochem Geophys Geosyst 14:540-555

Hidayati S, Ishihara K, lquchi M (2007) Volcano-tectonic earthquakes during the stage of magma accumulation at the Aira caldera, southern Kyushu, Japan. Bull Volcanol Soc Jpn 52(6):289-309

Hirata N, Matsu'ura M (1987) Maximum-likelihood estimation of hypocenter with origin time eliminated using nonlinear inversion technique. Phys Earth Planet Inter 47:50-61

Hotta K, Iguchi M, Ohkura T, Yamamoto K (2016) Multiple-pressure-source model for ground inflation during the period of high explosivity at Sakurajima volcano, Japan—combination analysis of continuous GNSS, tilt and strain data. J Volcanol Geotherm Res 310:12-25

Iguchi M (2013) Eruptive activity of Sakurajima volcano during the period from July 2012 to June 2013. Study on volcanic eruption process by multiparameter observation at Sakurajima, 1-8 (in Japanese with English abstract)

Iguchi M, Tameguri T, Ohta Y, Ueki S, Nakao S (2013) Characteristics of volcanic activity at Sakurajima volcano's Showa crater during the period 2006 to 2011. Bull Volcanol Soc Jpn 58(1):115-135

Jousset P, Mori H, Okada H (2003) Elastic models for the magma intrusion associated with the 2000 eruption of Usu Volcano, Hokkaido, Japan. JVolcanol Geotherm\ Res 125:81-106

Kamo K (1978) Some phenomena before the summit eruptions at Sakurajima volcano. Bull Volcanol Soc Jpn 23:53-64 (in Japanese with English abstract)

Mogi K (1958) Relations between the eruptions of various volcanoes and the deformations of the ground surfaces around them. Bull Earthq Res Inst 36:99-134

Morishita Yu, Kobayashi T, Yarai H (2016) Three-dimensional deformation mapping of a dike intrusion event in Sakurajima in 2015 by exploiting the right- and left-looking ALOS-2 InSAR. Geophys Res Lett. doi:10.1002/201 6GL068293

Okada Y (1992) Internal deformation due to shear and tensile faults in a half space. Bull Seismol Soc Am 82(2):1018-1040

Tiampo KF, Rundle JB, Fernandez J, Langbein JO (2000) Spherical and ellipsoidal volcanic sources at Long Valley caldera, California, using a genetic algorithm inversion technique. J Volcanol Geotherm Res 102:189-206

Watanabe T, Tabei T (2004) GPS velocity field and seismotectonics of the Ryukyu arc, southwest Japan. J Seismol Soc Jpn 57(1):1-10 (in Japanese with English abstract)

Wessel P, Smith WHF (1995) New version of Generic Mapping Tools released. Eos, Trans Am Geophy Union 76:329

Yamamoto K, Sonoda T, Takayama T, Ichikawa N, Ohkura T, Yoshikawa S, Inoue H, Matsushima T, Uchida K, Nakamoto M (2013) Vertical ground deformation with the volcanic activity of Sakurajima Volcano, Japan during 1996-2010 as revealed by repeated precise leveling surveys. Bull Volcanol Soc Jpn 58(1):137-151

Yokoo A, lguchi M, Tameguri T, Yamamoto K (2013) Processes prior to outburst of vulcanian eruption at Showa crater of Sakurajima volcano. Bull Volcanol Soc Jpn 58(1):163-181

Zhao S, Müller RD, Takahashi Y, Kaneda Y (2004) 3-D finite-element modelling of deformation and stress associated with faulting: effect of inhomogeneous crustal structures. Geophys J Int 157:629-644 